\title{
A feasibility analysis of waste heat recovery systems for marine applications
}

\author{
Francesco Baldi ${ }^{\mathrm{a}, *}$, Cecilia Gabrieliii ${ }^{\mathrm{a}}$ \\ ${ }^{a}$ Chalmers University of Technology; Department of Shipping and Marine Technology, \\ SE-41296 Gothenburg, Sweden.
}

\begin{abstract}
The shipping sector is today facing challenges which require a larger focus on energy efficiency and fuel consumption. In this article, a methodology for performing a feasibility analysis of the installation of a waste heat recovery (WHR) system on a vessel is described and applied to a case study vessel. The method proposes to calculate the amount of energy and exergy available for the WHR systems and to compare it with the propulsion and auxiliary power needs based on available data for ship operational profile. The expected exergy efficiency of the WHR system is used as an independent variable, thus allowing estimating the expected fuel savings when a detailed design of the WHR system is not yet available. The use of the proposed method can guide in the choice of the installation depending on the requirements of the owner in terms of payback time and capital investment. The results of the application of this method to the case study ship suggest that fuel savings of $5 \%$ to $15 \%$ can realistically be expected, depending on the sources of waste heat used and on the expected efficiency of the WHR system.
\end{abstract}

NOTE: This is the pre-print version of this scientific paper. For the official version please refer to the following publication:

Baldi F. and Gabrielii C., A feasibility analysis of waste heat recovery systems for marine applications, Energy (2015), Volume 1, pag. 654-665.

http://dx.doi.org/10.1016/j.energy.2014.12.020

Keywords:

Waste heat recovery, Marine Propulsion System, Feasibility Analysis, Operational Profile, low carbon shipping

\footnotetext{
*Corresponding author, 0046317722615

Email addresses: francesco.baldi@chalmers.se (Francesco Baldi), cecilia.gabrielii@chalmers.se (Cecilia Gabrielii)
} 


\section{Nomenclature}

\section{Acronyms}

AE Auxiliary engine

CMS Continuous monitoring systems

EGE Exhaust gas economiser

GB Gearbox

HT High temperature (cooling)

JW Jacket water

LO Lubricating oil

LT Low temperature (cooling)

ME Main engine

ORC Organic Rankine cycle

SG Shaft generator

SW Sea water (cooling)

WHR Waste heat recovery

\section{Subscripts}

$0 \quad$ Reference conditions

air air

Comp Compressor

Cool After cooler

cyl Cylinder

eg Exhaust gas

in Inlet

$\max$ Maximum

out Outlet

prod Products

prop Propeller

S Shaft 
Turb Turbine

\section{Variables}

$\beta \quad$ Compression ratio

$\Delta T_{p p} \quad$ Pinch point temperature difference $\left[{ }^{\circ} \mathrm{C}\right]$

$\dot{m} \quad$ Mass flow $[\mathrm{kg} / \mathrm{s}]$

$\dot{Q} \quad$ Heat flow $[\mathrm{kW}]$

$\eta \quad$ Efficiency

$\eta_{e n} \quad$ Energy efficiency

$\eta_{e x} \quad$ Exergy efficiency

$\eta_{p o l} \quad$ Polytropic efficiency

$\lambda \quad$ Engine load

c Specific heat (for liquids) $[\mathrm{kJ} / \mathrm{kgK}]$

$c_{p} \quad$ Specific heat at constant pressure (for gases) $[\mathrm{kJ} / \mathrm{kgK}]$

$T_{c} \quad$ Cold sink temperature $\left[{ }^{\circ} \mathrm{C}\right]$

EX Exergy $[\mathrm{kJ}]$

$\mathrm{h} \quad$ Specific enthalpy $[\mathrm{kJ} / \mathrm{kg}]$

$\mathrm{m} \quad$ Mass $[\mathrm{kg}]$

N Number

P Power, $[\mathrm{kW}]$

s Specific entropy $[\mathrm{kJ} / \mathrm{kgK}]$

$\mathrm{T} \quad$ Temperature $\left[{ }^{\circ} \mathrm{C}\right]$

$\mathrm{V} \quad$ Volume $\left[\mathrm{m}^{3}\right]$ 


\section{Introduction}

Shipping business has been expanding almost continuously in the last decades [1], and is today responsible for between $80 \%$ and $90 \%$ of the overall global trade [2]. When we observe that today global trade, compared to 1950, is more than 100 times larger in terms of volume and value of goods transported [3], the importance and role of shipping in today's economy becomes apparent. However, shipping is now subject to important challenges. Bunker fuel prices are today three times higher than they were in the 80's [4] and fuel costs are estimated to account for between $43 \%$ and $67 \%$ of total operating costs depending on vessel type [5]. Moreover, upcoming environmental regulations on sulphur oxides, nitrogen oxides and greenhouse gases will exert an additional leverage on fuel costs [6]. This phenomenon will be more pronounced in present and future emission controlled areas, i.e. USA coastal waters, the Baltic Sea, and the North Sea, where regulations will be stricter.

Various fuel saving solutions for shipping are available and currently implemented. Operational measures include improvements in voyage execution, engine monitoring, reduction of auxiliary power consumption, trim/draft optimization, weather routing, hull/propeller polishing, slow-steaming. Design measures can relate to the use of more efficient engines and propellers, improved hull design, air cavity lubrication, wind propulsion, fuel cells for auxiliary power generation, waste heat recovery, pump frequency converters, cold ironing [6]. Several scientific studies have been conducted on these technologies, and a more detailed treatise would be out of the scope of this work, which focuses particularly on the use of waste heat recovery (WHR).

Despite their high brake efficiency Diesel engines waste large amounts of heat to the environment, especially (but not only) in the exhaust gas. Several alternative ways to recover the waste energy produced by Diesel engine on board ships have been proposed and applied in the past [7]. The focus of this paper lies however in the utilisation of WHR for the supply of mechanical/electrical power to the ship. In spite of their still rather limited application in the shipping industry, WHR systems for auxiliary power generation have been widely studied in literature. When four-stroke engines are employed, the relatively high temperature in the exhaust gas $\left(\sim 320^{\circ} \mathrm{C}[8]\right)$ allows the employment of a standard steam cycle. This technology was explored, among others, by Theotokatos et al., who proposed a techno-economic evaluation of the application of a single-pressure steam cycle to bulk carriers [9] and to ferries [10]. Steam-based Rankine cycles have however been proposed also for application to two-stroke engines, in spite of the lower temperature of the exhaust gas after the turbocharger $\left(\sim 275^{\circ} \mathrm{C}\right.$, [8]). Ma et al. proposed and evaluated a single-pressure design, both in design conditions and at part-load [11]. A detailed thermo-economic optimization of a WHR system for a two-stroke engine powered containership based on a steam cycle was proposed by Dimopoulos et al. [12], who also investigated the application of exergy analysis as a mean to improve the understanding of the combined cycle (Diesel engine and WHR system) efficiency and the optimization procedure [13]. Grimmelius et al. proposed a modelling framework for evaluating the 
waste heat recovery potential of Diesel engines and tested it to marine applications [14]. Steam based WHR systems for both four- and two-stroke engines are available commercially, among others by MAN, Wärtsilä, Mitsubishi and Alfa Laval. Most of the proposed solutions also involve the use of a turbocharger bypass in connection with a power turbine, particularly effective at high engine load [12].

Organic Rankine cycles (ORCs) are considered as an alternative solution in the case of two-stroke engines given the low exhaust temperatures. ORCs are Rankine cycles employing a working fluid different from water in order to adapt evaporation and condensation temperatures to the heat source. Larsen et al. proposed a methodology for the simultaneous optimisation of the process design layout, working fluid and process parameters depending on the temperature of the heat source [15]; Choi and Kim analysed the performance of a dual-loop WHR system for a medium-sized containership under operational conditions [16], while Yang et al. analysed the performance at part-load and transient conditions for a larger vessel [17]. A comparison of conventional steam cycles with ORCs have been proposed by Hountalas et al. [18], while Larsen et al. also included Kalina cycles in the analysis [19,20]. These studies are of particular relevance since two-stroke engines are by far the most employed prime mover in the shipping industry in terms of installed power [21].

As seen in the previous paragraphs the exhaust gas is of major importance for the WHR potential of Diesel engines. Other sources of waste heat are also available, namely the cooling of combustion air after compression (charge air cooling, CAC), lubricating oil, and cylinder wall cooling water (jacket water, JW). The use of the exhaust gas alone is the most common configuration, and is often suggested both in scientific literature [11, 15-17] and as a "baseline" case by manufacturers. The use of charge air cooling water for working fluid preheating is also often suggested in literature $[9,10,12,14,18]$. Finally, Larsen et al. and some manufacturers propose the utilisation of heat from cylinder cooling on top of charge air and exhaust gas [15, 22].

With reference to different types of technologies, case studies, and designs, the previously mentioned works witness quite significant possibility for energy saving when WHR systems are employed, ranging from around $1 \%$ for singlepressure steam cycles applied to two-stroke engines [9] to more complex systems based on ORCs (up to 10\% [18]) or including the cooling systems as a source for waste heat (over $10 \%$ [13]).

Despite the acknowledgment of the importance of ship operational profile on WHR systems performance, this aspect is seldom accounted for in the technoeconomic or feasibility evaluation. Some of the authors do not include this part in their work $[15,17,19,20]$; when a techno-economic analysis is included, expected ship performance is often calculated based on a single operating point [11]. The approximation employed by Theotokatos et al. [9], Livanos et al. [10], Choi et al. [16], and Dimopoulos et al. [12, 13], which clearly identifies two or three operational speeds, is suitable for the ships operating according to fixed schedules (ferries [10] and container ships [12, 13, 16]); however, this might not hold true for other kinds of vessels with less predictable operational profiles. 
Ships such as tankers, bulk carriers and general cargo ships often operate in volatile markets [1]. Speed has a major influence on ship power demand (as a rule of thumb, propulsive power demand is a function of the third power of ship speed [23]) and is subject to large variations [24], mostly as a consequence of market evolution [1]; draft also remarkably influences ship power demand, and depending on the ship type it can vary sensibly between different voyages [1, 24]. Ambient variables, such as wave height and wind speed, are naturally stochastic and can easily double ship power demand for a given speed[25]. Auxiliary power requirement can vary substantially depending on the ship type [23] and on ship operations. Ship variable operations reflect on a wide range of engine loads, which in turn affect the WHR potential both in terms of the availability of waste heat and of recovery cycle efficiency. Steam cycles proposed by Theotokatos et al. show $75 \%$ drop in WHR power generation when decreasing engine load from $100 \%$ to $50 \%$ load [9]. Similar values are reported by other studies including off-design performance evaluations [10-12, 16].

As an initial step towards a more thorough inclusion of the complexity of ship operational profile in the design process of WHR systems, this study aims at proposing a simplified method for the evaluation of the WHR potential and of the related fuel savings for ships operating according to complex operational profiles. More specifically, this study aims at identifying whether the installation of a WHR system on board of a specific vessel could be profitable or not depending on the amount of waste heat available and on how the additional power generated by the WHR system can be used.

\section{Description of the investigated case study}

Operational data from a case study ship are used for demonstrating the application of the method. The selected ship is a Panamax chemical / product tanker. Figure 1 shows a conceptual representation of the ship energy generation systems, while relevant ship features are presented in Table 1. Measured data are available from a continuous monitoring system (CMS) installed by a private provider. The available data frequency is 1 point every 15 minutes of operation, derived from the averaging of an original sampling of 1 point every 15 seconds.

The ship is propelled by two MaK 8M32C four-stroke Diesel engines rated $3,840 \mathrm{~kW}$ each. The two main engines (ME) are connected to a common gearbox (GB). One of the GB outputs is connected to the controllable pitch propeller with the speed reduced from $600 \mathrm{rpm}$ to $105 \mathrm{rpm}$. The second output connects the GB to the shaft generator (SG) which provides $60 \mathrm{~Hz}$ current to the ship. Auxiliary power can also be generated by two auxiliary engines (AE) rated 682 $\mathrm{kW}$ each. Both the SG and the AEs are connected to a common switchboard. Auxiliary heat demand is fulfilled by a combination of exhaust gas economisers (EGE) and auxiliary oil-fired boilers.

Referring to the application of WHR, the main sources of waste heat generally are: exhaust gas, charge air cooling, cylinder cooling, and lubricating oil cooling [14]. On the case study ship, the exhaust gas is released in the atmosphere through the funnel after the EGE. All other sources of waste heat are 
handled by the cooling systems and released to the sea as warm water. The ship is provided with three interconnected cooling systems, namely the high temperature (HT), low temperature (LT), and sea water (SW) cooling. All the heat lost through the charge air cooling, the cylinder walls and the lubricating oil is transferred to these systems, which can therefore be considered as a "secondary" source of waste heat. A graphical representation of the energy flows in the system is provided in Figure 2, where values of temperature and mass flow are provided for all relevant flows at $85 \%$ engine load.

Only operations when the ship is sailing, both in loaded and in unloaded (ballast) conditions, are considered, therefore discarding the time spent in port and manoeuvring. The large variance in the propulsive power requirement showed in Figure 3a emphasises the need of taking the ship's operational profile in detailed account both in the design and retrofitting process. The auxiliary power demand is more uniform and is below $500 \mathrm{~kW}$ for $90 \%$ of sailing time (see Figure $3 \mathrm{~b}$ ). In the remaining $10 \%$ of the time, however, demand can increase up to $1500 \mathrm{~kW}$, in connection with operations of e.g. ballast pumps, cargo pumps, and auxiliary boilers.

\section{Methodology}

The procedure employed in this work is graphically described in Figure 4 and can be summarized as follows. First, measurements from ship operations are collected from the case study vessel. Second, said measurements are elaborated using ship technical documentation and applying physical principles to calculate the temperatures and mass flow rates of the different sources of waste heat available from the energy system and, consequently, to calculate energy and exergy flows. Third, the WHR system's ability to convert heat to power is represented by an estimated value of its exergy efficiency, and the power generated by the WHR system is calculated. Lastly, the comparison of the available WHR power with the propulsive and auxiliary power demand allows the calculation of the yearly ship fuel consumption with and without the installation of a WHR system. Since this study does not focus on one specific WHR system, steps 3 and 4 are repeated for different values of WHR exergy efficiency, which is used here as an independent variable of the problem.

\subsection{Propulsion and auxiliary power demand}

Main engine power is calculated according to Equation 1.

$$
P_{M E}=\frac{\frac{P_{p r o p}}{\eta_{S}}+\frac{P_{S G}}{\eta_{S G}}}{\eta_{G B}}
$$

Where the variables $P$ and $\eta$ refer to power and efficiency and subscripts prop and S respectively refer to the propeller and the propeller shaft. $P_{S G}$ and $P_{\text {prop }}$ are available from the CMS; $\eta_{S}$ is assumed equal to 0.99 , as suggested by Shi et al. [26]; $\eta_{G B}$ is assumed equal to 0.983 as reported by the shipyard

where the ship was built. Since on the case study ship the SG is dimensioned 
for high power demand when unloading the cargo, it often operates at low load. A polynomial regression calibrated on the curves proposed in [27] was therefore used in order to model SG efficiency as a function of load; a value of $95 \%$ is assumed for SG design efficiency as reported on technical documentation.

Ships require the generation of both heat and power for auxiliary systems. Auxiliary power demand is measured by the CMS. Auxiliary heat demand was not available from direct measurements and was estimated based on technical data and on available measured values for air and sea water temperatures. Auxiliary heat is generated from waste heat in the exhaust gas by the EGE, and limits the amount of energy and exergy available for recovery.

\subsection{WHR power}

Waste heat on the case study vessel is available from a number of separate sources. Three alternatives are considered and compared in this study, depending on which of such sources are used for energy recovery: the exhaust gas (A), the exhaust gas and the HT cooling systems (B), and all primary waste heat sources (Exhaust gas, Charge air cooling, Jacket water cooling, Lubricating oil cooling. Case C). Alternative A represents the most standard and easy-to-retrofit solution; alternative B represents the state of the art [22, 28]; finally, alternative $\mathrm{C}$ represents the upper boundary, where the highest amount of exergy is available for recovery.

According to the most common arrangement for WHR systems, the recovered power is used for fulfilling auxiliary power demand [9-11]. When additional power is available, the possibility of contributing to main propulsion is often accounted for $[12,29]$. The additional design/retrofitting effort for allowing this possibility lies in the installation of a shaft generator that can also operate as an electric motor. This solution is not uncommon in the shipping sector, mostly for adding both redundancy and flexibility to the propulsion system [23]. The conversion of the shaft generator to a generator/motor was therefore also explored in the current study.

\subsubsection{Exergy analysis}

Exergy is defined as the maximum shaft work that can be done by a system in a specified reference environment [30]. For electrical, potential, kinetic, and mechanical energy, exergy and energy flows are normally assumed to coincide; chemical exergy differs from energy only when chemical reactions are involved, which is not relevant in this work. In the case of thermal energy, instead, energy and exergy content are substantially different. For a given amount of matter, its thermal exergy content is defined as showed in Equation 2.

$$
\dot{E X}=\dot{m}\left[\left(h-h_{0}\right)+T_{0}\left(s-s_{0}\right)\right]
$$

EX, h, and s respectively represent specific exergy, enthalpy, and entropy. The subscript 0 refers to reference conditions, which in this work coincide with measurements of sea water temperature. Starting from the knowledge of the waste heat mass flows and temperatures and from the assumption of all gas 
flows behaving as perfect gases an alternative form for the calculation of exergy flows can be derived as shown by equation 3 .

$$
\dot{E X}=\dot{m} c_{p}\left[\left(T-T_{0}\right)-T_{0}\left(\ln \frac{T}{T_{0}}\right)\right]
$$

Only few variables related to waste heat availability are measured by the CMS; the equations, regressions and approximations employed for the calculation of the temperatures and the mass flow rates are provided in Tables 2 and 3 ; the structure of the main engine and its cooling systems is shown in Figure 2, where values for flow rates and temperatures calculated according to the method presented in Table 2 are provided for $85 \%$ load of the propulsion system. The coefficients related to the amount of energy wasted in the jacket water and lubricating oil are calibrated on engine technical data at full power and are assumed to be load independent.

The set of equations presented in Tables 2 and 3 results in ship waste exergy flows being available as $E X\left(\dot{m}_{f u e l}, \lambda_{M E}, T_{S W}\right)$. An example of the resulting flows at a sea water temperature of $20{ }^{\circ} \mathrm{C}$ is shown in Figure 5. The sharp transition that can be observed at $45 \%$ load is caused by the shift from one- to two-engines operations.

Figure 6 shows an extract of 10 days from the dataset used in this work for propulsive power demand, auxiliary power demand, auxiliary heat demand, and for the available exergy from waste flows (exhaust, and whole ship systems). Figure 6 therefore provides a visualisation of the high variability in both available WHR power and ship power demand.

\subsubsection{Exergy efficiency}

The exergy related to a specific flow represents the amount of power that could be generated using the flow as the hot source of a Carnot cycle. Exergy efficiency, defined according to equations 4 and 5 , can be used as a representation of the approach of a system to ideal [30]. Compared to energy efficiency, exergy efficiency does not depend on the temperature of the heat source and can be more easily used to compare WHR systems which harvest heat at different temperatures [30].

$$
\begin{aligned}
\eta_{e x} & =\frac{E X_{\text {prod }}}{E \dot{X}_{i n}} \\
\eta_{e x} & =\frac{\eta_{\text {en }}}{\eta_{\text {Carnot }}}
\end{aligned}
$$

In this study the exergy efficiency is used as a parameter which represents the technological level of the recovery system. According to this assumption, WHR systems with low and high exergy efficiency will be respectively referred to as "low-level" and "high level". The exergy efficiency of the systems can be related to different factors: complexity of the thermodynamic cycle, quality of the individual components, size of the heat exchangers. All these factors are 
supposed to contribute to the total exergy efficiency of the system in relation to their cost (i.e. any improvement that increases exergy efficiency is also expected to increase investment costs proportionally). The existence of a relationship between exergy flows and costs was first proposed by Tsatsaronis and Pisa [31] and is currently often employed under the name of exergo-economic analysis.

Reference values for the exergy efficiency of WHR systems can be derived from existing publications. Theotokatos and Livanos propose single-pressure steam cycles having design exergy efficiencies of respectively around $35 \%$ to $38 \%[9,10]$; values for ORCs as proposed by Larsen et al. [19] can reach exergy efficiencies of around $60 \%$; Choi and Kim [16] compare a single-pressure steam cycle and a combination of a steam and an ORC cycle, reporting exergy efficiencies of respectively $37 \%$ and $61 \%$. The range of exergy efficiency for the analysis was therefore set between $30 \%$ and $70 \%$ so to consider from today's standard design practice to latest technological improvement. The efficiency of state of the art ORCs is estimated using the regressions proposed by Larsen et al. [32] (Equation 6).

$$
\eta_{\text {reg }}=a_{0}+a_{1} T_{\text {in }}+a_{2} T_{\text {out }}+a_{3} \eta_{\text {pol }}+a_{4} \Delta T_{p p}+a_{5} T_{c}
$$

where the term $\eta_{p o l}$ refers to the polytropic efficiency of the expander in the recovery cycle, $\Delta T_{p p}$ to the minimum pinch point temperature difference and $T_{c}$ to the temperature of the cold sink. Coefficients for Equation 6 can be found in [32] and vary depending on the inlet temperature of the heat source.

\subsection{Performance parameters}

The main performance parameter employed in this study is the reduction of fuel consumption over one year of operations of the selected case study vessel compared to the operations in absence of any WHR system installed.

The percentage of time during which the vessel equipped with a WHR system is able to generate the totality of the auxiliary power demand was also considered; this performance parameter allows to give a better estimation of the increased/reduced need for maintenance connected to the installation of a WHR system. This aspect is particularly of interest because on the selected case study the rotational speed of the engine (and, therefore, of the propeller) is fixed by the requirements of the shaft generator to operate at constant speed. When the WHR system is able to provide all the required auxiliary power and the SG can be shut off, the engine and the propeller can operate at variable speed, thus allowing more efficient operations. This condition is not rare for vessels in the size range as the ship under study, and it has been proved that substantial savings can be achieved by operating CPP propeller ships at variable propeller speed [33, 34]. Information such as average load and running time can also be interested when auxiliary engines are used for auxiliary power generation, as in this case the installation of a WHR system would reduce costs related to maintenance and spare parts.

Finally, an economic evaluation was performed. According to a survey performed by DNV among ship owners, $75 \%$ of the respondents to the survey considered 5 years to be the limit to the payback time for a retrofitting technology 
and 2 years for the remaining 25\% [6]. This information can be used in order to calculate an upper boundary for the investment cost of a WHR system given the payback time and its exergy efficiency. The results of the exergy analysis are used to estimate operational savings, under the assumption that other costs and savings than those related to fuel consumption can be considered as negligible. A price of $600 \mathrm{USD} / \mathrm{t}$ for marine fuel was employed in the analysis [35]. The maximum purchase price is consequently estimated as shown in Equation 7.

$$
C_{\text {max }}=N_{\text {years }} \sum_{i} \dot{m}_{f u e l, i} \phi_{i} \Delta t
$$

where $N_{\text {years }}$ represents the number of years considered in the payback time calculation, $\dot{m}_{f u e l, i}$ the fuel flow and $\phi_{i}$ the expected fractional savings at the instant $i$, and $\Delta t$ the duration of each time interval.

\section{Results}

Figures 7 to 11 show the results of the application of the method to the case study. All results are presented as a function of the exergy efficiency of the WHR cycle, and for the six alternative arrangements based on the waste heat sources harvested and on the final use of the WHR power as summarised in Table 4.

Figure 7 a shows that between $40 \%$ to $90 \%$ of the yearly auxiliary energy demand can be expected to be generated by the WHR system. However, Figure 7a also shows that for higher WHR power the auxiliary power demand tends to get saturated. This phenomenon is clearly shown in Figure 8, where the curves related to the arrangements where WHR power is solely used for fulfilling auxiliary power demand $(\mathrm{A} 1, \mathrm{~B} 1, \mathrm{C} 1)$ tend to reach an asymptote. This phenomenon is more evident for the $\mathrm{B}$ and $\mathrm{C}$ arrangements, where more WHR power is available. When recovering on the exhaust gas alone, as also shown in Figure $7 \mathrm{~b}$, the power available for propulsion is very limited (less then $0.5 \%$ of total propulsion power demand at 0.5 exergy efficiency) and does not justify the installation of means for the utilisation of exceeding WHR power on the only basis of fuel consumption. If the results related to the use of all primary waste energy sources (C) represent an ideal maximum for energy recovery, it should be noted that when the HT cooling is also used as waste energy source (B) there is a substantial amount of WHR power that would be lost if no means for using WHR power for propulsion are put in place. For an exergy efficiency of 0.5 , almost $2 \%$ reduction of propulsive power demand can be achieved in this case.

Figure 9 represents the expected reduction in yearly fuel consumption compared to the baseline case (no WHR installed) and confirms what presented in the previous figures. Fuel savings from $4 \%$ to $8 \%$ can be expected in realistic conditions (arrangements A and B, exergy efficiency up to 0.5), while a theoretical maximum of $16 \%$ savings for arrangement $\mathrm{C}$ at 0.7 exergy efficiency could be reached.

Figure 10 shows the percentage of sailing time during which the WHR system provides sufficient power for the auxiliaries. Figure 10 suggests that it is not 
possible to fulfil both heat and power needs based on the exhaust gas alone unless very complex recovery systems are employed (e.g. dual-cycle ORC cycles with regeneration). A lower exergy efficiency become sufficient when more waste heat sources are recovered; when all available heat sources from the main engines are harvested a rather simple cycle of 0.4 exergy efficiency can suffice to cover the whole auxiliary power demand for more than $80 \%$ of the time spent sailing.

The economic evaluation as described in Section 3.3 is presented in Figure 11. Here, the maximum capital cost which allows a 5-years payback time is shown. The values represented in Figure 11 should be seen as a guidance for the ship owner interested in the possibility of installing a WHR system for the evaluation of solution proposed by different manufacturers as a function of past ship operations, characteristics of the installed propulsion plant and exergetic performance of the proposed WHR system.

Values for the both energy and exergy efficiencies of optimised ORC systems as suggested by Larsen et al. [32] were also shown in Figures 8, 9 and 11 and are summarised in Table 5 . The efficiencies that can be reached by ORCs optimised for the specific temperature range from $53 \%$ (B case) to $65 \%$ (A case). These values represent state-of-the-art ORCs and thus give an indication of today technical limits. If WHR systems with such efficiencies were to be installed on the selected case study, yearly fuel savings of $7-14 \%$ could be achieved depending on the selected arrangement.

\section{Discussion}

The results of this study suggest that from an analysis of ship operational profile and of its influence on the potential benefits from the installation of a WHR system it is possible to give an early estimation of how much fuel consumption can be reduced in connection to different alternative systems. This allows to have an initial indication of what type of arrangement should be studied first depending on the type of vessel, operations, and on company investment strategies.

In the case studied during this work the results showed that between $5 \%$ and $8 \%$ fuel savings can realistically be achieved through the use of WHR systems on the selected vessel. The order of magnitude of these results is in agreement to what presented in other studies found in available literature on the subject $[9,10,12,18]$. However, the results of the analysis vary sensibly when the operational profile is taken into account. Theotokatos and Livanos [9] propose the installation of a single-pressure system having an average exergy efficiency of 0.35 on a vessel, which is assumed to operate at $85 \%$ load for $98 \%$ of the sailing time. Analysing the case study proposed in this work under the same assumptions results in a total yearly reduction in fuel consumption of $263 \mathrm{t}$ (158 kUSD) per year, compared to the $189 \mathrm{t}$ (113 kUSD) per year calculated using a more complex operational profile, giving a substantial $39 \%$ difference. Hence, the approximation of constant load proves viable for ferries (as in the case investigated by Theotokatos and Livanos) but not for ships operated on a more variable schedule, such as the case analysed in this study. 
The application of the feasibility analysis proposed in this study provided additional insight on the type of installation that should be planned. Two main alternatives are identified that best fit the case study. If resources for new investments are limited, a rather simple WHR system with relatively low efficiency and positioned on the exhaust funnel can be used for the generation of auxiliary power demand on board. Such solution would be relatively cheap and simple and could be performed through a modification of the already existing exhaust gas economiser. If there are possibilities for large investments the use of the HT cooling as a source of waste heat is advised, in particular if connected to the retrofitting of the shaft generator for its possible use as shaft motor. The higher expected investment cost, in this case, would be justified by larger savings. In this second case the possibility of using WHR power for propulsion is suggested, especially if a high-efficiency system is installed.

This study assumes the exergy efficiency of WHR systems to be constant with load. In this sense, the exergy efficiencies represented in Figures 9 to 11 should be seen as average efficiencies of the WHR system. This approximation is justified by noting that exergy efficiency is less load-dependent than energy efficiency; nevertheless, further work should be directed to the accounting of off-design performance.

When compared to previous work in literature, this study employs a high detail in the accounting of the operational profile and it improves the reliability of the results in terms of long-term benefits, as stressed in the previous parts of this work. However, this approach heavily relies on the availability of extensive measurements from the continuous monitoring system. Even though the method is flexible to incomplete datasets, as demonstrated in this study, it relies on inlet data quality for providing insightful analysis and conclusions. In addition, the whole basic assumption that using past ship operations provides a better estimation of future operations can also be challenged and discussed; ship operational pattern can vary substantially over time, as showed for instance by Banks et al. [24].

\section{Conclusion}

In this paper a method for the estimation of the potential benefits of installing waste heat recovery systems, to be used in the early stages of the retrofitting or the design of a ship, was proposed. The method includes the elaboration of on board measurements in order to calculate the available amount of waste heat, and an exergy analysis for the estimation of the actual amount of useful power that can be recovered. The use of on board measurements ensures that the effect of the operational profile of the ship on the expected benefits

from the installation of a WHR system is accurately captured, an aspect that can become of primary importance in today's volatile shipping market. The application to the case study of a chemical tanker shows that the method can provide important information to the initial phase of the decision making process, when the question lies more in deciding whether the WHR system should be installed or not rather than on which pressure it should operate at. 
Using the method proposed in this paper, preliminary results related to the reduction of fuel consumption, avoided use of auxiliary generation equipment and to the capital cost range that would make the WHR installation profitable in a 2- and 5- years horizon could be obtained. In the specific case studied in the paper, fuel savings from $4 \%$ to $16 \%$ can be achieved, which results in the maximum investment cost ranging between 0.5 and 1.8 MUSD for a 5-years payback time. These results depend on the sources of waste heat employed (exhaust gas, charge air cooling, various types of cooling systems), on the type of complementary auxiliary generation system (shaft generator or auxiliary engines), and on the exergy efficiency of the recovery system. According to the analysis, two main solutions should be considered: either a simple WHR system based on the exhaust gas (low investment cost, low yearly savings) or a more complex system also recovering on the HT cooling systems and with the possibility of using excess WHR power for propulsion (higher investment cost, higher yearly savings)

\section{Acknowledgments}

This work is part of a larger project about ship energy systems modeling, performed at the Shipping and Marine Technology Department of Chalmers University of Technology and financed by the Swedish Energy Agency. The authors would also like to thank Bengt-Olof Petersen and Laurin Maritime for their support and discussions. A special acknowledgment is also given to Ulrik Larsen from Chalmers University of Technology and professor Gerasimos Theotokatos from the University of Stratchlyde for the very profitable discussions and reviews of the work.

\section{References}

[1] A. Branch, M. Stopford, Maritime economics, Routledge, New York, USA, 2013.

[2] UNCTAD, Review of maritime transport, Tech. rep., United Nations Conference on Trade and Development, Geneva, Switzerland (2012).

[3] WTO, International trade statistics, Tech. rep., WorldTrade Organization (WTO), Geneva, Switzerland (2012).

[4] M. Mazraati, Challenges and prospects of international marine bunker fuels demand, OPEC Energy Review 35 (1) (2011) 1-26.

[5] J. Kalli, T. Karvonen, T. Makkonen, Sulphur content in ships bunker fuel in 2015: A study on the impacts of the new imo regulations and transportation costs, Tech. rep., Ministry of Transport and Communications, Helsinki, Finland (2009).

[6] DNV, Shipping 2020, Tech. rep., Det Norske Veritas, Oslo, Norway (2012). 
[7] G. Shu, Y. Liang, H. Wei, H. Tian, J. Zhao, L. Liu, A review of waste heat recovery on two-stroke ic engine aboard ships, Renewable and Sustainable Energy Reviews 19 (2013) 385-401.

[8] K. Mollenhauer, H. Tschoeke, Handbook of Diesel engines, Springer, Heidelberg, Germany, 2010.

[9] G. Theotokatos, G. A. Livanos, Techno-economic analysis of single pressure exhaust gas waste heat recovery systems in marine propulsion plants, Proceedings of the Institution of Mechanical Engineers Part M: Journal of Engineering for the Maritime Environment 227 (2) (2013) 83-97.

[10] G. Livanos, G. Theotokatos, D. Pagonis, Techno-economic investigation of alternative propulsion plants for ferries and roro ships, Energy Conversion and Management 79 (2014) 640 - 651.

[11] Z. Ma, D. Yang, Q. Guo, Conceptual design and performance analysis of an exhaust gas waste heat recovery system for a 10000teu container ship, Polish Maritime Research 19 (2) (2012) 31-38.

[12] G. Dimopoulos, C. Georgopoulou, N. Kakalis, Modelling and optimization of an integrated marine combined cycle system, in: Proceedings of the 24th International Conference on Energy, Cost, Optimization, Simulation and Environmental Impact of Energy Systems (ECOS), Novi Sad, Serbia, 2011, pp. 1283-1298.

[13] G. Dimopoulos, C. Georgopoulou, N. Kakalis, The introduction of exergy analysis to the thermo-economic modelling and optimisation of a marine combined cycle system, in: Proceedings of the 25th International Conference on Energy, Cost, Optimization, Simulation and Environmental Impact of Energy Systems (ECOS), Perugia, Italy, 2012, paper No 61.

[14] H. Grimmelius, E. Boonen, H. Nicolai, D. Stapersma, The integration of mean value first principle diesel engine models in dynamic waste heat and cooling load analysis, in: CIMAC Congress, Bergen, Norway, 2010, paper No 280 .

[15] U. Larsen, L. Pierobon, F. Haglind, C. Gabrielii, Design and optimisation of organic rankine cycles for waste heat recovery in marine applications using the principles of natural selection, Energy 55 (2013) 803-812.

[16] B. C. Choi, Y. M. Kim, Thermodynamic analysis of a dual loop heat recovery system with trilateral cycle applied to exhaust gases of internal combustion engine for propulsion of the 6800 teu container ship, Energy (58) (2013) 404-416.

[17] D. Yang, R. Hu, Z. Ma, Part-load analysis of waste heat recovery system for a 10000teu container ship, International Journal of Heat and Technology 31 (1) (2013) 121-128. 
[18] D. Hountalas, C. Katsanos, G. Mavropoulos, Efficiency improvement of large scale 2-stroke diesel engines through the recovery of exhaust gas using a rankine cycle, Procedia-Social and Behavioral Sciences 48 (2012) 14441453.

[19] U. Larsen, F. Haglind, O. Sigthorsson, A comparison of advanced heat recovery power cycles in a combined cycle for large ships, in: Proceedings of the 26th International Conference on Energy, Cost, Optimization, Simulation and Environmental Impact of Energy Systems (ECOS), Guilin, China, 2013.

[20] U. Larsen, T. Nguyen, T. Knudsen, F. Haglind, System analysis and optimisation of a kalina split-cycle for waste heat recovery on large marine diesel engines, Energy 64 (2014) 484-494.

[21] B. Haight, Marine propulsion order survey, Tech. rep., Diesel and Gas Turbines Worldwide, Last accessed online 22-09-2014 at http://www. dieselgasturbine.com/images/customdata/2847_2.pdf (2012).

[22] MAN, Waste heat recovery system (whrs) for reduction of fuel consumption, emissions and eedi, Tech. rep., MAN Diesel and Turbo, Copenhagen, Denmark (2011).

[23] A. Molland, The Maritime Engineering Reference Book: A Guide to Ship Design, Construction and Operation, Butterworth-Heinemann, 2008.

[24] C. Banks, O. Turan, A. Incecik, G. Theotokatos, S. Izkan, C. Shewell, $\mathrm{X}$. Tian, Understanding ship operating profiles with an aim to improve energy efficient ship operations, in: Low Carbon Shipping Conference, London, UK, 2013.

[25] J. Prpić-Oršić, O. Faltinsen, Estimation of ship speed loss and associated co2 emissions in a seaway, Ocean Engineering 44 (2012) 1-10.

[26] W. Shi, D. Stapersma, H. T. Grimmelius, Analysis of energy conversion in ship propulsion system in off-design operation conditions, WIT transactions on Ecology and the Environment 121 (2009) 449-460.

[27] W. McCarthy, W. Peters, D. Rodger, Marine diesel power plants practices, Tech. rep., Jersey City, USA, technical and Research Bulletin 1990:3-49 (1990).

[28] Wärtislä, Wärtsilä auxpac product guide, Tech. rep., Wärtislä Finland, Vaasa, Finland (2011).

[29] F. Burel, R. Taccani, N. Zuliani, Improving sustainability of maritime transport through utilization of liquefied natural gas (lng) for propulsion, Energy (57) (2013) 412-420. 
[30] I. Dincer, M. Rosen, Exergy: Energy, Environment and Sustainable Development, 2nd Edition, Elsevier, Amsterdam, Netherlands, 2013.

[31] G. Tsatsaronis, J. Pisa, Exergoeconomic evaluation and optimization of energy systems: application to the cgam problem, Energy 19 (3) (1994) $287-321$.

[32] U. Larsen, L. Pierobon, J. Wronski, F. Haglind, Multiple regression models for the prediction of the maximum obtainable thermal efficiency of organic rankine cycles, Energy 65 (2014) 503-510.

[33] F. Baldi, U. Larsen, C. Gabrielii, K. Andersson, Analysis of the influence of the engine, propeller and auxiliary generation interaction on the energy efficiency of controllable pitch propeller ships, in: International Conference of Maritime Technology (ICMT), Glasgow, UK, 2014.

[34] G. Tian, A. Juando, J. Heslop, M. Solla, T. Roskilly, A. Sarasquete, J. Rodriguez, A holistic model for variable speed generation systems on a roro vessel, in: Low Carbon Shipping Conference, Newcastle, UK, 2012.

[35] EIA, Annual energy outlook, Tech. rep., U.S. Energy Information Administration, Washington DC, USA (2013). 


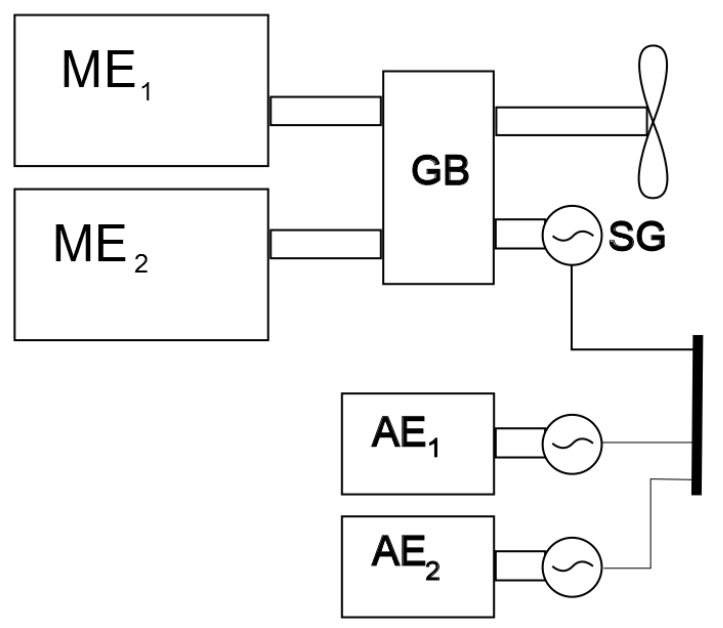

Figure 1: Conceptual representation of ship propulsion system

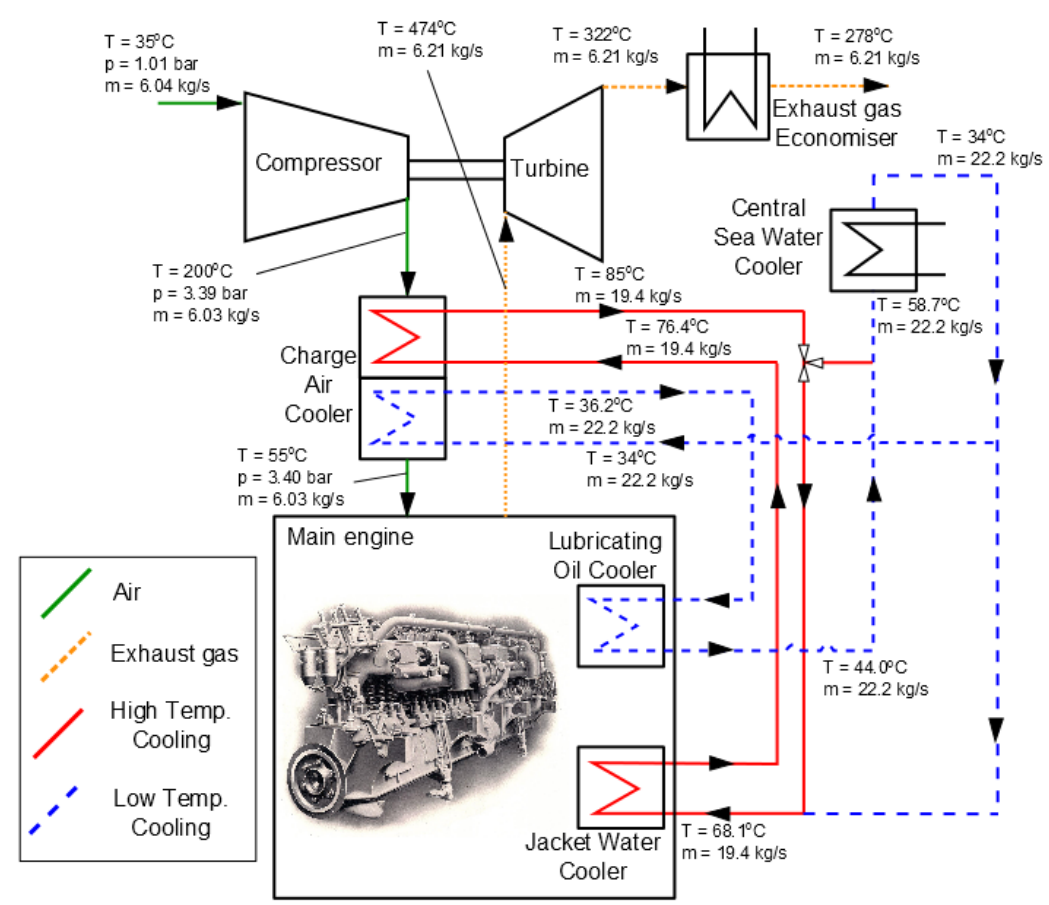

Figure 2: Graphical representation of main engine cooling systems and heat flows 


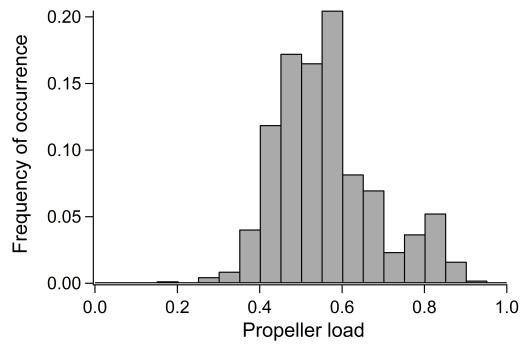

(a) Propeller load

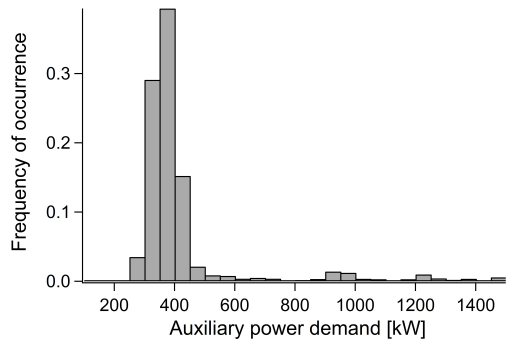

(b) Auxiliary power demand

Figure 3: Load distributions for the propulsion system and the auxiliary power demand

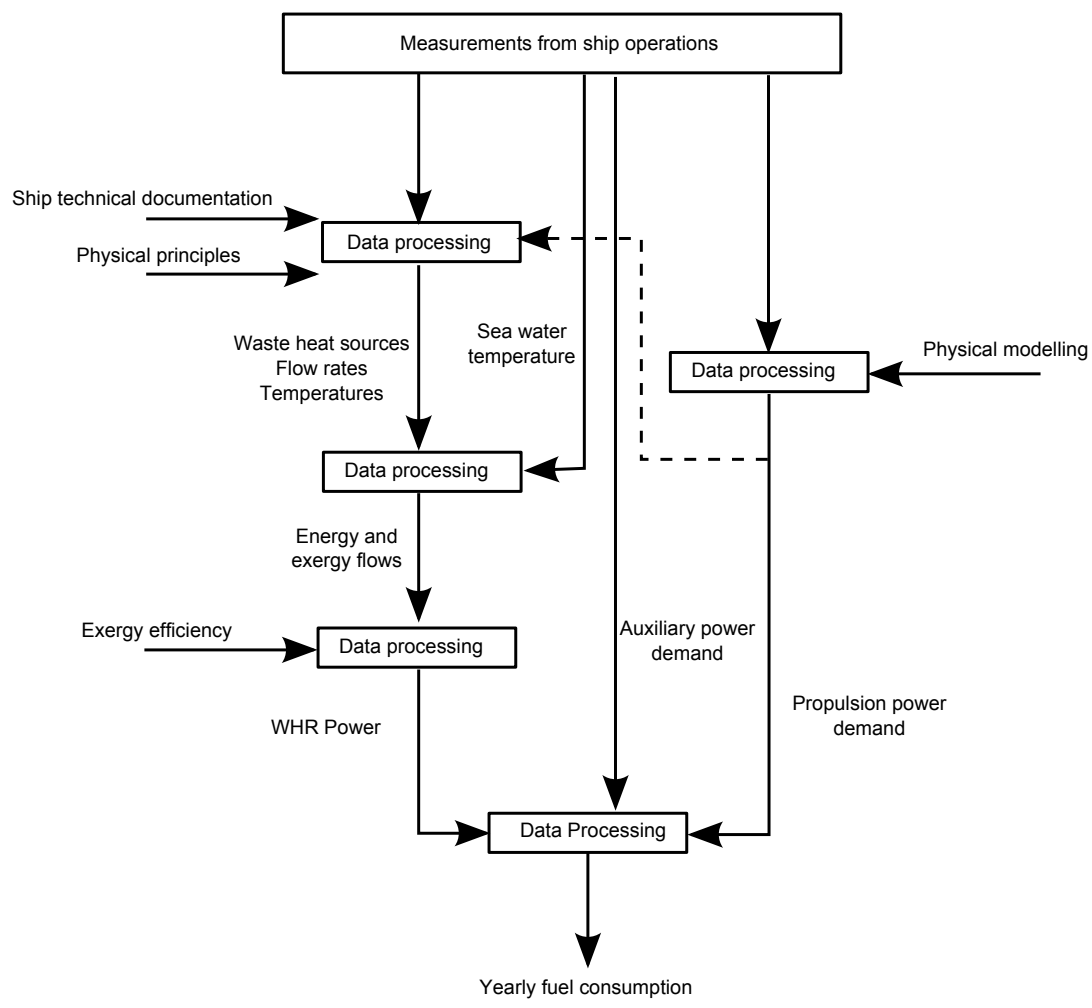

Figure 4: Methodology 


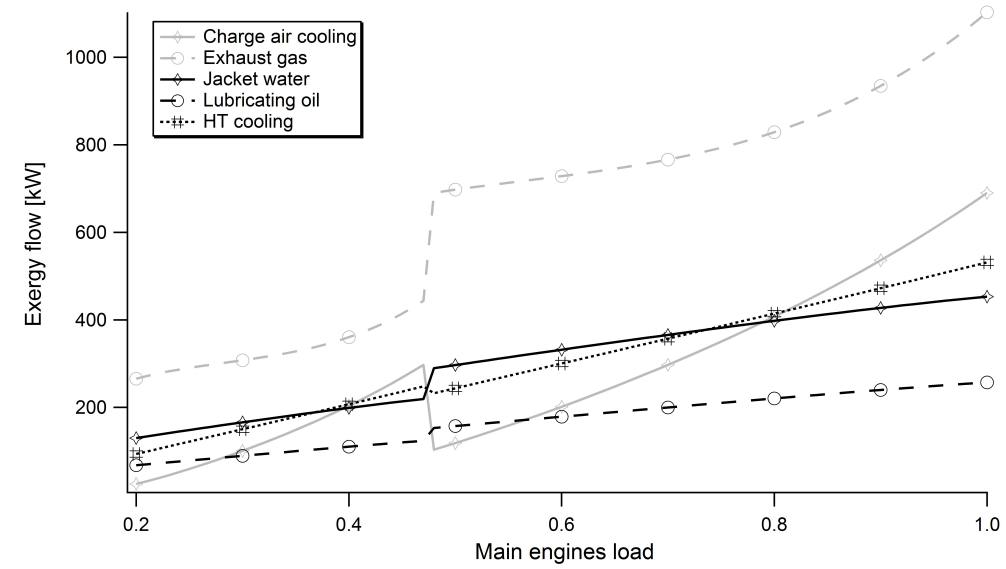

Figure 5: Waste exergy flows versus main engines load

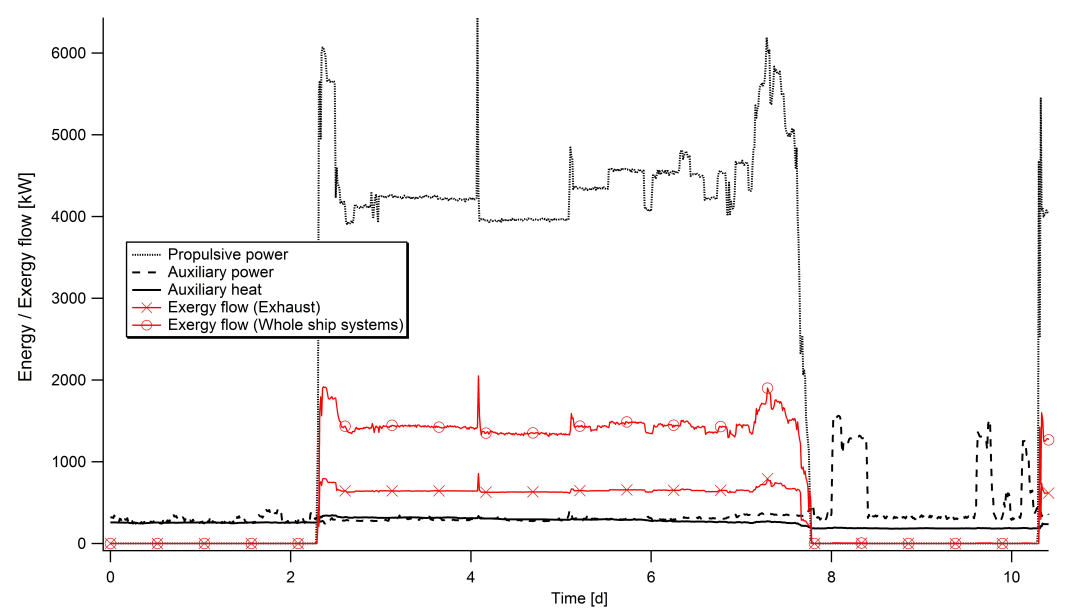

Figure 6: Extract of 10 days from the available dataset, showing power demand and waste exergy flows

\begin{tabular}{lrr}
\hline Ship feature & Value & Unit \\
\hline Deadweight & 47,000 & $\mathrm{t}$ \\
Installed power (Main Engines) & $3,840(\mathrm{x} 2)$ & $\mathrm{kW}$ \\
Installed power (Auxiliary Engines) & $682(\mathrm{x} 2)$ & $\mathrm{kW}$ \\
Shaft generator design power & 3,200 & $\mathrm{~kW}$ \\
Exhaust boilers design steam gen. & 1,400 & $\mathrm{~kg} / \mathrm{h}$ \\
Auxiliary boilers design steam gen. & 28,000 & $\mathrm{~kg} / \mathrm{h}$ \\
\hline
\end{tabular}

Table 1: Main features of the case study ship 


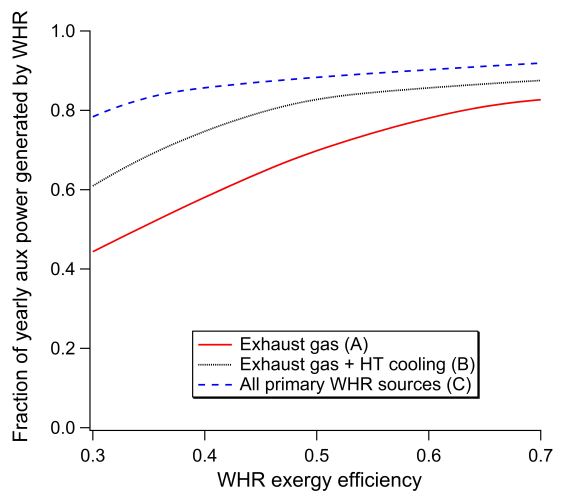

(a) Auxiliary Power

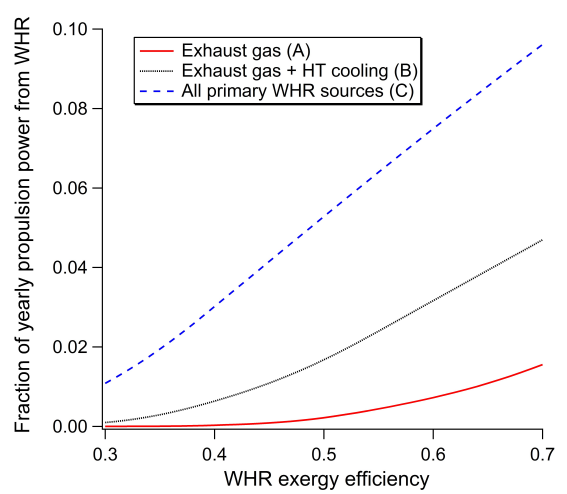

(b) Propulsion

Figure 7: Fraction of yearly energy demand generated by the WHR system

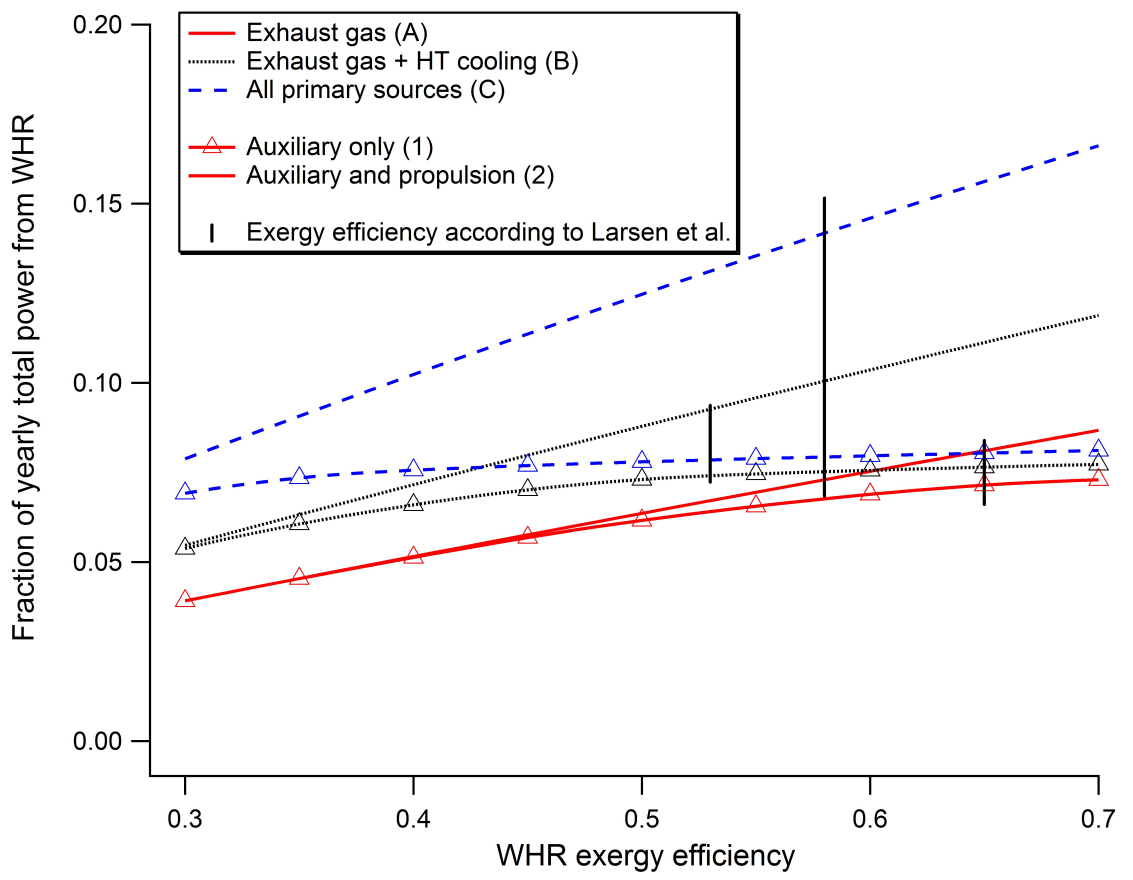

Figure 8: Fraction of yearly total energy demand generated by the WHR system 


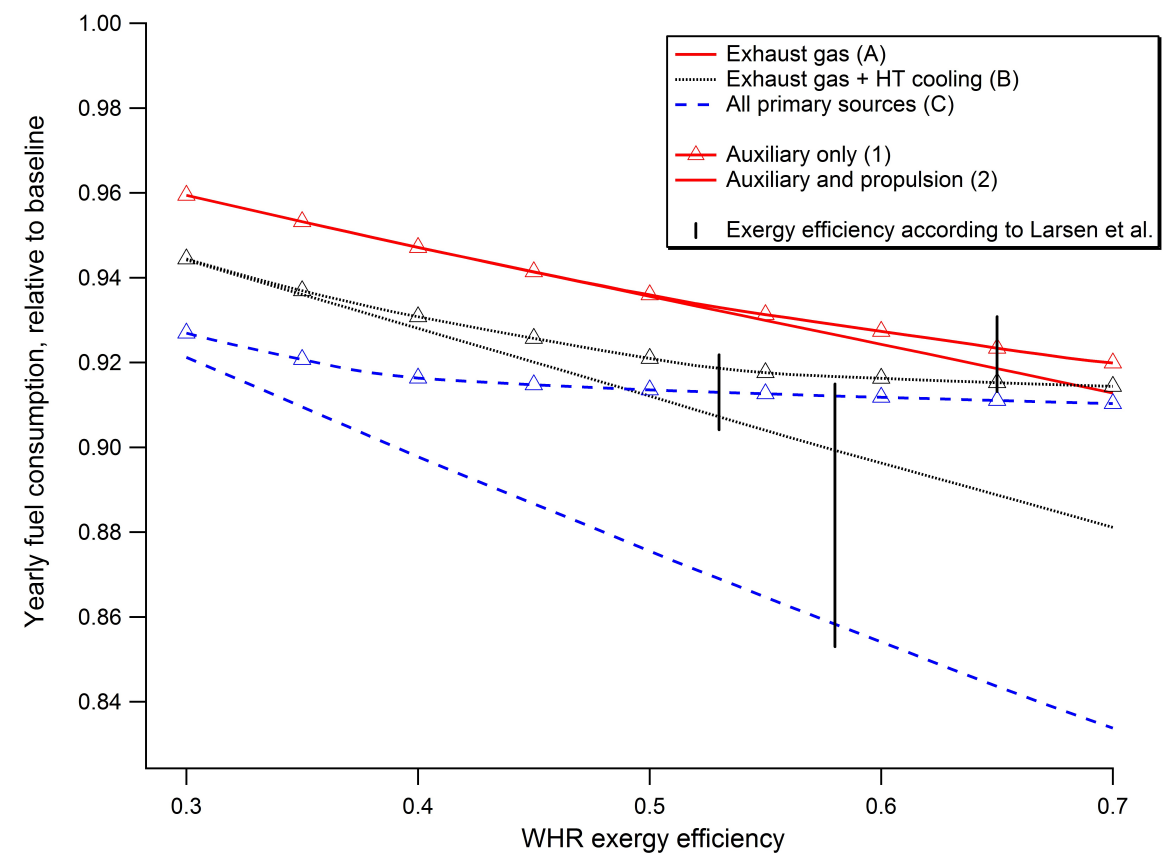

Figure 9: Expected reduction of yearly fuel consumption

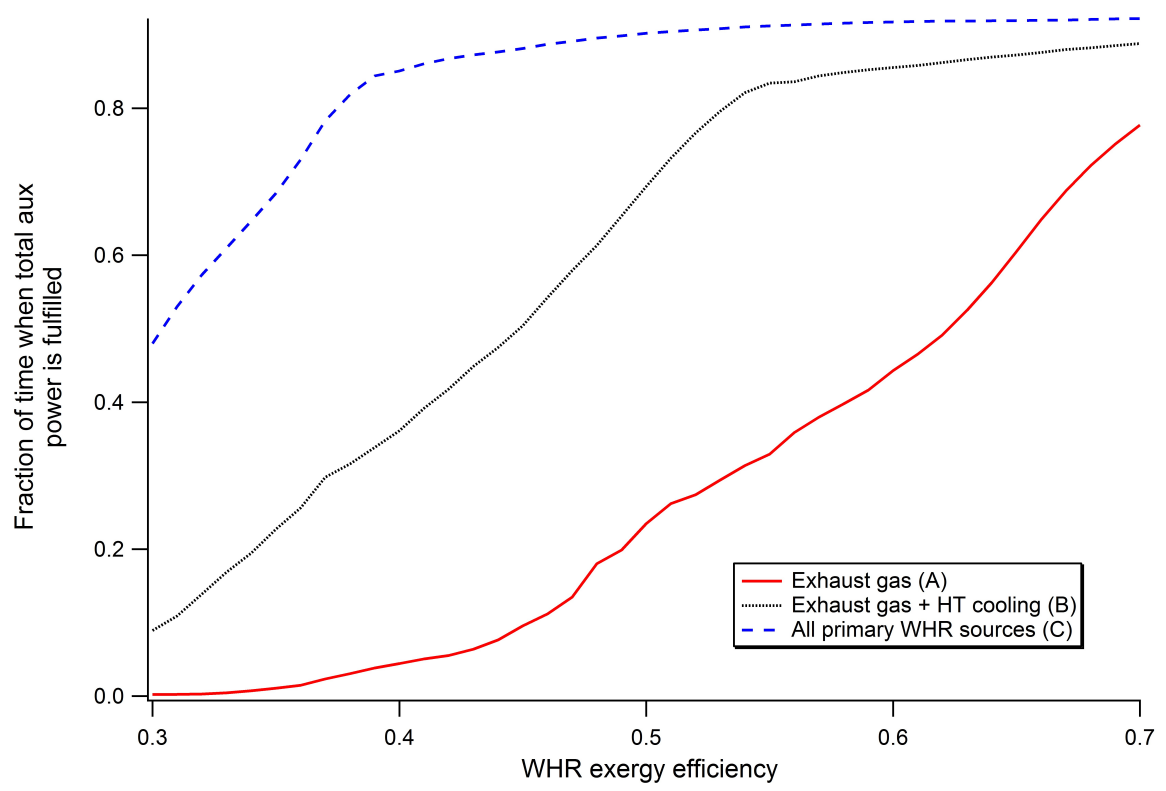

Figure 10: Fraction of yearly time spent sailing during which the WHR system is able to provide the whole auxiliary power demand 


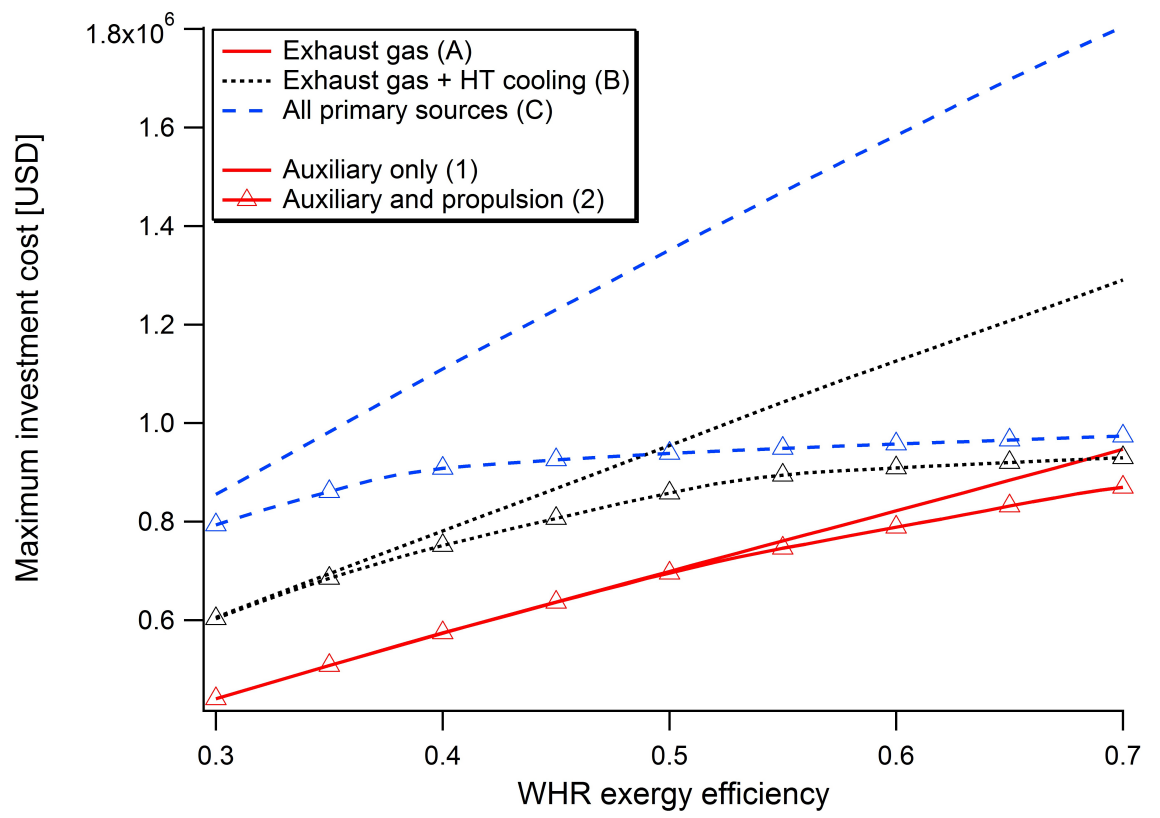

Figure 11: Maximum capital cost for a 5-years payback time as a function of WHR system exergy efficiency 


\begin{tabular}{|c|c|c|c|}
\hline Component & Variable & Equation & Eq.\# \\
\hline Air & $\begin{array}{l}\text { Temperature, before compressor } \\
\text { Temperature, after compressor } \\
\text { Temperature, after CAC } \\
\text { Mass flow rate }\end{array}$ & $\begin{array}{l}T_{a i r, C o m p, i n}=35^{\circ} C[27]_{k-1} \\
T_{a i r, C o m p, \text { out }}=T_{i n} \beta^{\frac{k \eta_{p o l, c o m p}}{\eta}} \\
T_{a i r, C A C, \text { out }}=55^{\circ} C[27] \\
\dot{m}_{\text {air }}=N_{M E} \rho_{\text {in }} \frac{\omega_{M E}}{120} V_{c y l, \text { max }} N_{c y l}\end{array}$ & $\begin{array}{l}(8) \\
- \\
(9)\end{array}$ \\
\hline Compressor & $\begin{array}{l}\text { Compression ratio } \\
\text { Polytropic efficiency }\end{array}$ & $\begin{array}{l}\beta_{\text {comp }}=a_{\text {Beta }, 0}+a_{\text {Beta }, 1} \lambda_{M E} \\
\eta_{p o l, c o m p}=a_{e t a, 0}+a_{e t a, 1} \lambda_{M E}+a_{e t a, 2} \lambda_{M E}^{2}\end{array}$ & $\begin{array}{l}(10) \\
(11)\end{array}$ \\
\hline Exhaust gas & $\begin{array}{l}\text { Temperature, after turbine } \\
\text { Temperature, before EGE } \\
\text { Temperature, after EGE } \\
\text { Mass flow rate }\end{array}$ & $\begin{array}{l}T_{e g, T u r b, \text { out }}=a_{e g, 0}+a_{e g, 1} \lambda_{M E}+a_{e g, 2} \lambda_{M E}^{2} \\
T_{e g, E G E, \text { in }}=T_{\text {eg }, \text { out }}+\frac{\dot{Q}_{a u x, h e a t}}{\dot{m}_{e g} c_{p, e g}} \\
T_{e g, E G E, \text { out }}=150^{\circ} C \\
\dot{m}_{e g}=\dot{m}_{\text {air }}+\dot{m}_{\text {fuel }}\end{array}$ & $\begin{array}{l}(12) \\
(13) \\
- \\
(14)\end{array}$ \\
\hline Lub oil & $\begin{array}{l}\text { Temperature, after cooler } \\
\text { Temperature, before cooler } \\
\text { Mass flow rate }\end{array}$ & $\begin{array}{l}T_{L O, \text { Cool }, \text { out }}=60^{\circ} C \\
T_{L O, C o o l, \text { in }}=T_{L O, a C}+\frac{\dot{Q}_{L O}}{c_{L O} \dot{m}_{L O}} \\
\dot{m}_{L O}=65 \frac{\mathrm{m}^{3}}{\mathrm{~h}}\end{array}$ & $\begin{array}{l}- \\
(15) \\
-\end{array}$ \\
\hline HT cooling & $\begin{array}{l}\text { Temperature, after cooler } \\
\text { Temperature, before cooler } \\
\text { Mass flow rate }\end{array}$ & $\begin{array}{l}T_{H T, C o o l, \text { in }}=T_{H T, b C}-\frac{\dot{Q}_{L O}}{c_{H T} \dot{m}_{H T}} \\
T_{H T, C o o l, o u t}=90^{\circ} C \\
\dot{m}_{H T}=70 \frac{m^{3}}{h}\end{array}$ & $\begin{array}{l}(16) \\
- \\
-\end{array}$ \\
\hline LT cooling & $\begin{array}{l}\text { Temperature, after cooler } \\
\text { Temperature, before cooler } \\
\text { Mass flow rate }\end{array}$ & $\begin{array}{l}T_{L T, C o o l, \text { out }}=34^{\circ} \mathrm{C} \\
T_{L T, \text { Cool }, \text { in }}=T_{L T, \text { Cool }, \text { out }}+\frac{\dot{Q}_{L T}}{c_{L T} \dot{m}_{L T}} \\
\dot{m}_{L T}=80 \frac{\mathrm{m}^{3}}{h}\end{array}$ & $\begin{array}{l}- \\
(17) \\
-\end{array}$ \\
\hline
\end{tabular}

Table 2: Physical equations, regressions and assumptions employed in the exergy analysis

\begin{tabular}{llll}
\hline Type & Waste heat source & Equation & Eq.\# \\
\hline Primary & Exhaust gas & $\dot{Q}_{e g}=\dot{m}_{e g} c_{p, e g}\left(T_{e g, T u r b, o u t}-T_{0}\right)$ & $(18)$ \\
Primary & CAC & $\dot{Q}_{C A C}=\dot{m}_{\text {air }} c_{p, \text { air }}\left(T_{\text {air }, \text { Comp out }}-T_{\text {air }, \text { CAC, out }}\right)$ & $(19)$ \\
Primary & Jacket water cooling & $\dot{Q}_{J W}=0.414\left(\dot{Q}_{\text {fuel }}-\dot{W}_{e g}-\dot{Q}_{C A C}\right)$ & $(20)$ \\
Primary & Lubricating oil cooling & $\dot{Q}_{L O}=0.444\left(\dot{Q}_{f u e l}-\dot{W}-\dot{Q}_{e g}-\dot{Q}_{C A C}\right)$ & $(21)$ \\
Secondary & HT cooling & $\dot{Q}_{H T}=\dot{Q}_{J W}+0.776 \dot{Q}_{C A C}$ & $(22)$ \\
Secondary & LT cooling & $\dot{Q}_{L T}=\dot{Q}_{C A C}+\dot{Q}_{J W}+\dot{Q}_{L O}$ & $(23)$ \\
\hline
\end{tabular}

Table 3: Equations and assumptions employed for the calculation of waste heat flows 


\begin{tabular}{|c|c|c|}
\hline Case & Waste heat source(s) & WHR power use \\
\hline A1 & Exhaust Gas & Auxiliary power \\
\hline A2 & Exhaust gas & $\begin{array}{l}\text { Auxiliary power } \\
\text { Propulsion }\end{array}$ \\
\hline B1 & $\begin{array}{l}\text { Exhaust Gas } \\
\text { HT cooling }\end{array}$ & Auxiliary power \\
\hline B2 & $\begin{array}{l}\text { Exhaust Gas } \\
\text { HT cooling }\end{array}$ & $\begin{array}{l}\text { Auxiliary Power } \\
\text { Propulsion }\end{array}$ \\
\hline C1 & $\begin{array}{l}\text { Exhaust Gas } \\
\text { Charge air cooling } \\
\text { Lubricating Oil Cooling }\end{array}$ & Auxiliary Power \\
\hline $\mathrm{C} 2$ & $\begin{array}{l}\text { Exhaust Gas } \\
\text { Charge air cooling } \\
\text { Lubricating Oil Cooling }\end{array}$ & $\begin{array}{l}\text { Auxiliary Power } \\
\text { Propulsion }\end{array}$ \\
\hline
\end{tabular}

Table 4: Summary of alternative arrangements

\begin{tabular}{rrr}
\hline Waste heat sources & $\eta_{e n}$ & $\eta_{e x}$ \\
\cline { 2 - 3 } Exhaust gas & 0.29 & 0.65 \\
Exhaust gas + HT cooling & 0.18 & 0.53 \\
All primary sources & 0.18 & 0.58 \\
\hline
\end{tabular}

Table 5: Energy and exergy efficiencies for optimal ORC calculated according to Larsen et al. [32] 


\begin{tabular}{|c|c|c|c|c|c|c|c|c|c|}
\hline & & \multicolumn{2}{|l|}{$\eta_{e x}$} & \multicolumn{6}{|c|}{ Alternatives } \\
\hline & & & Baseline & A1 & A2 & B1 & B2 & $\mathrm{C} 1$ & $\mathrm{C} 2$ \\
\hline Propulsion demand & {$[\mathrm{TJ}]$} & & 60.46 & 60.46 & 60.46 & 60.46 & 60.46 & 60.46 & 60.46 \\
\hline Auxiliary demand & {$[\mathrm{TJ}]$} & & 6.03 & 6.03 & 6.03 & 6.03 & 6.03 & 6.03 & 6.03 \\
\hline \multirow{4}{*}{ Main engine output } & \multirow{4}{*}[\mathrm{TJ}]{} & 0.3 & \multirow{4}{*}{68.32} & 65.53 & 65.53 & 64.49 & 64.47 & 63.23 & 62.82 \\
\hline & & 0.4 & & 64.68 & 64.69 & 63.51 & 63.32 & 62.56 & 61.21 \\
\hline & & 0.5 & & 63.88 & 63.86 & 62.85 & 62.20 & 62.37 & 59.69 \\
\hline & & 0.6 & & 63.3 & 63.1 & 62.6 & 61.1 & 62.2 & 58.2 \\
\hline \multirow{4}{*}{$\begin{array}{l}\text { WHR energy to } \\
\text { auxiliaries }\end{array}$} & \multirow{4}{*}[\mathrm{TJ}]{} & 0.3 & \multirow{4}{*}{-} & 2.67 & 2.67 & 3.67 & 3.67 & 4.73 & 4.73 \\
\hline & & 0.4 & & 3.50 & 3.50 & 4.50 & 4.50 & 5.17 & 5.17 \\
\hline & & 0.5 & & 4.21 & 4.21 & 4.99 & 4.99 & 5.33 & 5.33 \\
\hline & & 0.6 & & 4.71 & 4.71 & 5.16 & 5.16 & 5.44 & 5.44 \\
\hline \multirow{4}{*}{$\begin{array}{l}\text { SG energy to } \\
\text { auxiliaries }\end{array}$} & \multirow{4}{*}[\mathrm{TJ}]{} & 0.3 & \multirow{4}{*}{6.03} & 3.36 & 3.36 & 2.36 & 2.36 & 0.00 & 1.30 \\
\hline & & 0.4 & & 2.53 & 2.53 & 1.53 & 1.53 & 0.00 & 0.86 \\
\hline & & 0.5 & & 1.82 & 1.82 & 1.04 & 1.04 & 0.00 & 0.70 \\
\hline & & 0.6 & & 1.32 & 1.32 & 0.87 & 0.87 & 0.00 & 0.59 \\
\hline \multirow{4}{*}{$\begin{array}{l}\text { WHR energy to } \\
\text { propulsion }\end{array}$} & \multirow{4}{*}[\mathrm{TJ}]{} & 0.3 & \multirow{4}{*}{ - } & 0 & 0.00 & 0 & 0.06 & 0 & 0.66 \\
\hline & & 0.4 & & 0 & 0.02 & 0 & 0.38 & 0 & 1.82 \\
\hline & & 0.5 & & 0 & 0.13 & 0 & 1.01 & 0 & 3.19 \\
\hline & & 0.6 & & 0 & 0.44 & 0 & 1.91 & 0 & 4.53 \\
\hline \multirow{4}{*}{ Total WHR energy } & \multirow{4}{*}[\mathrm{TJ}]{} & 0.3 & \multirow{4}{*}{ - } & 2.67 & 2.68 & 3.67 & 3.73 & 4.73 & 5.38 \\
\hline & & 0.4 & & 3.50 & 3.52 & 4.50 & 4.89 & 5.17 & 6.99 \\
\hline & & 0.5 & & 4.21 & 4.34 & 4.99 & 6.00 & 5.33 & 8.52 \\
\hline & & 0.6 & & 4.71 & 5.14 & 5.16 & 7.08 & 5.44 & 9.97 \\
\hline \multirow{4}{*}{$\begin{array}{l}\text { Total fuel } \\
\text { consumption }\end{array}$} & \multirow{4}{*}[\mathrm{t}]{} & 0.3 & \multirow{4}{*}{4021} & 3,857 & 3,857 & 3,797 & 3,796 & 3,727 & 3,704 \\
\hline & & 0.4 & & 3,808 & 3,808 & 3,742 & 3,731 & 3,684 & 3,609 \\
\hline & & 0.5 & & 3,763 & 3,762 & 3,703 & 3,667 & 3,673 & 3,520 \\
\hline & & 0.6 & & 3,728 & 3,716 & 3,684 & 3,604 & 3,666 & 3,434 \\
\hline \multirow{4}{*}{$\begin{array}{l}\text { Complete fulfilment } \\
\text { auxiliary demand }\end{array}$} & \multirow{4}{*}[\mathrm{h}]{} & 0.3 & \multirow{4}{*}{-} & 8 & 8 & 366 & 377 & 1,966 & 1,962 \\
\hline & & 0.4 & & 182 & 186 & 1,480 & 1,508 & 3,486 & 3,509 \\
\hline & & 0.5 & & 962 & 958 & 2,841 & 2,833 & 3,696 & 3,704 \\
\hline & & 0.6 & & 1,815 &, 1808 & 3,505 & 3,514 & 3,759 & 3,762 \\
\hline \multirow{4}{*}{ Yearly savings } & & 0.3 & & 98 & 98 & 134 & 135 & 176 & 190 \\
\hline & [kUUD] & 0.4 & - & 128 & 127 & 167 & 174 & 202 & 247 \\
\hline & {$[\mathrm{K} \cup \mathrm{ND}]$} & 0.5 & - & 155 & 155 & 191 & 212 & 209 & 300 \\
\hline & & 0.6 & & 175 & 183 & 202 & 250 & 213 & 352 \\
\hline & & 0.3 & & 489 & 489 & 670 & 673 & 881 & 950 \\
\hline installation cost & [kUSD] & 0.4 & & 638 & 637 & 835 & 868 & 1009 & 1233 \\
\hline (5-year payback) & ] & 0.5 & - & 773 & 777 & 953 & 1060 & 1043 & 1501 \\
\hline & & 0.6 & & 876 & 913 & 1010 & 1251 & 1064 & 1760 \\
\hline
\end{tabular}

Table 6: Numerical results of the feasibility analysis 